\title{
A cross-sectional study of sexual dysfunction in chinese mainland female patients with rheumatoid arthritis
}

\author{
Congcong Zhou $\mathbb{C}^{-}$ \\ Changzhou Vocational Institute of Textile and Garment, Faculty of Humanities, Changzhou, China
}

\begin{abstract}
Objectives: This study aims to investigate the effects of rheumatoid arthritis (RA) on Chinese mainland female patients' sexual function compared with healthy subjects and to determine the risk factors of sexual dysfunction.

Patients and methods: A total of 151 female RA patients (mean age: $46.3 \pm 8.6$ years) and 146 healthy female controls (mean age $45.7 \pm 7.6$ years) were included in this cross-sectional study whose data were collected consecutively by questionnaires between November 2017 and June 2019 . Data were collected by using demographics, disease-related information, Female Sexual Function Index, Dyadic Adjustment Scale, Medical Coping Modes Questionnaire, other psychological parameters and the Short Form-36.

Results: Our results showed that the prevalence of female sexual dysfunction was $67.5 \%$ in RA patients, which was significantly higher than the controls $(54.1 \%)(p<0.05)$. Body mass index, resignation coping style, physical component summary, marital dysfunction and postmenopausal status were significant correlation factors by backward stepwise binary logistic regression.

Conclusion: Rheumatoid arthritis negatively affected sexual function of patients who had considerably impaired sexual function compared to controls.
\end{abstract}

Keywords: Chinese mainland patients, female, rheumatoid arthritis, sexual dysfunction.

Rheumatoid arthritis (RA) is chronic autoimmune disease with a higher prevalence among females, characterized as pathological changes such as inflammation and progressed joint injury. ${ }^{1,2}$ Several studies have indicated that RA affected different aspects of patients' life quality, including sexual dysfunction. ${ }^{3-5}$

Sexual dysfunction, a neglected area of life quality rarely appearing in quality of life or physical function questionnaires, ${ }^{6}$ may conversely deteriorate stress, self-identity and general health and cause reduced life quality. ${ }^{7}$ More importantly, it can determine roles, sex, and shape lifestyle of patients at all ages with RA. ${ }^{8}$ Despite the essential role of sexual dysfunction, it is interesting to find that sexual dysfunction has not received enough attention from healthcare professionals or the patients themselves. A recent review summarized that only $12 \%$ of patients were screened for sexual dysfunction when treated in a clinic. ${ }^{9}$ Due to the lack of suitable places to ask and time constraints, nurses barely give guidance on sexual dysfunction. ${ }^{10}$ From the view of patients, out of frustration or shame, they seldom report their sexual dysfunction. ${ }^{11}$ What is worse, few Chinese researchers are willing to explore sexual dysfunction among Chinese patients considering the conservative Asian culture. All of these have highlighted the importance of studying sexual dysfunction among Chinese patients with RA.

Received: February 26, 2020 Accepted: September 09, 2020 Published online: December 10, 2020

Correspondence: Congcong Zhou. Changzhou Vocational Institute of Textile and Garment, Faculty of Humanities, 213000 Changzhou, China. Tel: 8618862808680 e-mail: 15062815956@163.com 
Up to now, only a small part of studies have revealed the rate of female sexual dysfunction (FSD), ranging from 29.4 to $93.7 \%$ among patients with RA, ${ }^{12-14}$ which indicated the severity and diversity of the problem in different areas. However, the rate and risk factors of FSD in Chinese mainland RA patients have remained unknown. Therefore, in order to maintain the comparability of the results, we added agematched control subjects in our study.

Previous studies revealed that several factors were responsible for FSD in patients with RA such as suffering from longer disease duration, ${ }^{15,16}$ experiencing more clinical symptoms ${ }^{16-18}$ and certain psychological problems like depression, low self-esteem and anxiety. ${ }^{12,15}$ Other factors such as drug usage also possibly result in FSD. ${ }^{19}$ Nevertheless, few studies have included marital quality and coping style factors in this topic. However, marital quality and sexual dysfunction were linked closely in other researches, ${ }^{20-22}$ it is therefore for us to hypothesize that marital quality has effects on FSD. Lin et al. ${ }^{23}$ suggested that future studies should be conducted including coping style when investigating FSD in RA patients. To our knowledge, there are few studies concerning the relationship between FSD and coping style. Therefore, to overcome the divergent image of the available studies, we attempted to incorporate the possible clinical factors, marital quality and psychological problems like coping style to identify the related variables of FSD in our study. Hence, in this study, we aimed to investigate the effects of RA on Chinese mainland female patients' sexual function compared with healthy subjects and to determine the risk factors of sexual dysfunction.

\section{PATIENTS AND METHODS}

A total of 220 female RA patients and 211 healthy female subjects were included in this cross-sectional study, while 69 patients and 65 healthy controls were excluded because they reported no sexual intercourse within the recent one month. All data were collected consecutively by face-to-face questionnaires conducted with 151 RA patients (mean age: $46.3 \pm 8.6$ years) and 146 healthy controls (mean age $45.7 \pm 7.6$ years) between November 2017 and June 2019 at the Affiliated Hospital of
Nantong University. All patients (i) met the 2012 American College of Rheumatology diagnostic criteria, (ii) were aged $\geq 18$ years, (iii) married females, (iv) sexually active within the recent one month, $(v)$ displaying no other serious diseases that might block the results of this study, (vi) without any cognitive impairments and able to express their own thoughts in Mandarin freely. The study protocol was approved by the Ethics Committee of the Affiliated Hospital of Nantong University (approval number: 2017-k003). A written informed consent was obtained from each participant. The study was conducted in accordance with the principles of the Declaration of Helsinki.

Socio-demographic factors in self-reported questionnaires included age, body mass index (BMI), educational level, occupational status, average annual income, religious beliefs, smoking use and menopausal status. The disease activity levels, pain levels and functional disability for disease-related factors were investigated respectively by the Disease Activity Score 28 (DAS28), the 0-10 cm Visual Analog Scale (VAS) and the score of Health Assessment Questionnaire-Disability Index (HAQ-DI). The DAS28 included four parts of erythrocyte sedimentation rate, swelling and tenderness of 28 joint index and VAS for general disease activity. This measurement was confirmed as a valid and reliable tool and the higher the score, the more active was the disease. ${ }^{24}$ We used HAQ-DI to evaluate the functional disability in patients with RA, which includes 20 entries ranging from a score of 0 (no disability) to 3 (completely disability). The Chinese version of HAQ-DI has a high Cronbach's alpha of 0.86 , which is a reliable and valid measurement. ${ }^{25}$ Other disease-related factors of morning stiffness time and disease duration were also included.

Sexual dysfunction was evaluated by the Female Sexual Function Index (FSFI), which includes 19 items, six domains of desire, arousal, lubrication, orgasm, satisfaction and pain. Scores of FSFI range from 2 to 36, patients who scored below 26.55 were evaluated to have sexual dysfunction. ${ }^{26}$ The Cronbach's alpha of the Chinese version was 0.91 and this is a reliable and valid instrument for the Chinese population. ${ }^{23}$ The Dyadic Adjustment Scale 
(DAS) was used to evaluate marital quality. It includes 32 items with four domains of dyadic satisfaction, dyadic consensus, affectional expression and dyadic cohesion. Scores of DAS range from 0 to 151 , and the cut-off score was 107. Higher score represents better marital quality. The Chinese version of DAS has good reliability and validity. ${ }^{27,28}$ As described previously, ${ }^{29}$ coping style was used in the Medical Coping Modes Questionnaire (MCMQ), which contains 20 items, three coping subscales of confrontation, avoidance and resignation. The total score ranges from 8 to 32 , and a four-point Likert scale referring to never, sometimes, often and always was used in each item. The Hospital Anxiety and Depression Scale (HADS), a 14-item scale which was divided into two subscales of HADS-anxiety and HADS-depression, has good reliability and validity with Cronbach's alpha of 0.85 in the Chinese population. ${ }^{30}$ Scores for each subscale range from 0 to 21 , with higher scores representing higher levels of psychological disorder. ${ }^{31}$ The 36-Item Short Form Survey (SF-36) is a brief questionnaire which contains 36 items and two subscales of Physical Component Scale (PCS) and Mental Component Scale (MCS) with higher scores representing better health. ${ }^{32}$ As previous studies described, ${ }^{33}$ Rosenberg Self Esteem Scale, which contains 10 items with higher scores representing higher levels of self-esteem, was used to assess self-esteem.

Table 1. Baseline characteristics of RA patients and healthy controls

\begin{tabular}{|c|c|c|c|c|c|c|c|c|c|c|c|c|}
\hline \multirow[b]{2}{*}{ Variables } & \multicolumn{5}{|c|}{ RA patients $(\mathrm{n}=151)$} & \multicolumn{5}{|c|}{ Healthy controls $(n=146)$} & \multirow[b]{2}{*}{$t / Z / \chi^{2}$} & \multirow[b]{2}{*}{$p$} \\
\hline & $\mathrm{n}$ & $\%$ & Mean \pm SD & Median & IQR & $\mathrm{n}$ & $\%$ & Mean \pm SD & Median & IQR & & \\
\hline Age (year) & & & $46.3 \pm 8.6$ & & & & & $45.7 \pm 7.6$ & & & 0.612 & 0.543 \\
\hline BMI $\left(\mathrm{kg} / \mathrm{m}^{2}\right)$ & & & $22.9 \pm 3.6$ & & & & & $21.2 \pm 3.0$ & & & -0.637 & 0.525 \\
\hline $\begin{array}{l}\text { Education level }(\%) \\
\leq 9 \text { years } \\
>9 \text { years }\end{array}$ & $\begin{array}{l}98 \\
53\end{array}$ & $\begin{array}{l}64.9 \\
35.1\end{array}$ & & & & $\begin{array}{l}84 \\
62\end{array}$ & $\begin{array}{l}57.5 \\
42.5\end{array}$ & & & & 1.698 & 0.193 \\
\hline $\begin{array}{l}\text { Occupational status (\%) } \\
\text { Employed } \\
\text { Unemployed }\end{array}$ & $\begin{array}{l}94 \\
57\end{array}$ & $\begin{array}{l}62.3 \\
37.7\end{array}$ & & & & $\begin{array}{c}103 \\
43\end{array}$ & $\begin{array}{l}70.5 \\
29.5\end{array}$ & & & & 2.288 & 0.130 \\
\hline $\begin{array}{l}\text { Average annual } \\
\text { income yuan (\%) } \\
\quad<15,000 \\
\quad \geq 15,000\end{array}$ & $\begin{array}{l}74 \\
77\end{array}$ & $\begin{array}{l}49 \\
51\end{array}$ & & & & $\begin{array}{l}66 \\
80\end{array}$ & $\begin{array}{l}45.2 \\
54.8\end{array}$ & & & & 0.430 & 0.512 \\
\hline Religious beliefs (\%) & 16 & 10.6 & & & & 11 & 7.5 & & & & 0.842 & 0.359 \\
\hline Smoking use (yes) & 1 & 0.67 & & & & 0 & 0 & & & & 0.970 & 0.325 \\
\hline Menopausal status (yes) & 66 & 43.7 & & & & 50 & 34.2 & & & & 2.792 & 0.095 \\
\hline Morning stiffness (min) & & & & 5 & 60 & & & & & & & \\
\hline Disease duration (year) & & & & 5 & 12.8 & & & & & & & \\
\hline HAQ-DI score & & & & 0.3 & 1.0 & & & & & & & \\
\hline DAS28 score & & & & 4.1 & 0.1 & & & & & & & \\
\hline VAS pain (range 0-100) & & & & 5 & 4 & & & & & & & \\
\hline Confrontation & & & & 21 & 6 & & & & & & & \\
\hline Avoidance & & & & 17 & 4 & & & & & & & \\
\hline Resignation & & & & 9 & 6 & & & & & & & \\
\hline HADS-anxiety & & & & 6 & 6 & & & & 2.5 & 4.25 & -6.761 & $0.000^{*}$ \\
\hline HADS-Depression & & & & 4 & 7 & & & & 2 & 4 & -5.142 & $0.000^{*}$ \\
\hline Self-esteem score & & & & 31 & 5 & & & & 33 & 2 & -7.112 & $0.000^{*}$ \\
\hline PCS & & & & 43 & 27.75 & & & & 90 & 13.81 & -12.845 & $0.000^{*}$ \\
\hline MCS & & & & 48.21 & 38.25 & & & & 84.88 & 13.25 & -10.932 & $0.000^{*}$ \\
\hline Marital dysfunction & & & & 36 & 23.8 & & & & 8 & 5.5 & 19.83 & $0.000^{*}$ \\
\hline
\end{tabular}


Table 2. Evaluation of FSFI scores between RA patients and healthy controls

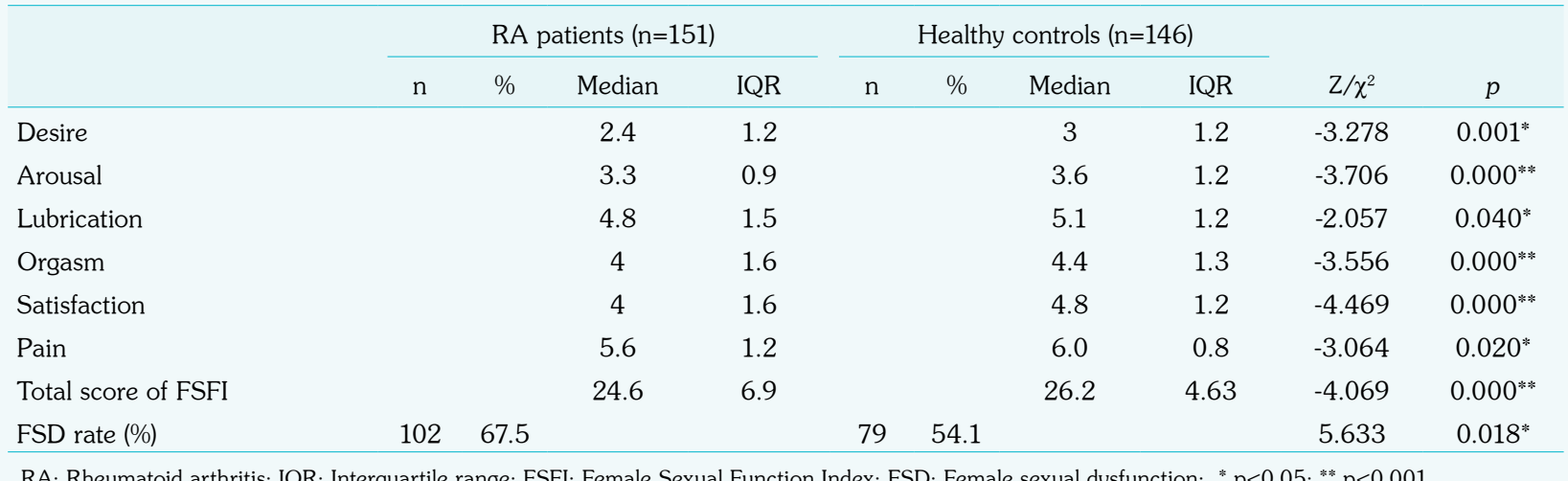

RA: Rheumatoid arthritis; IQR: Interquartile range; FSFI: Female Sexual Function Index; FSD: Female sexual dysfunction; ${ }^{*} \mathrm{p}<0.05 ;{ }^{* *} \mathrm{p}<0.001$.

Table 3. Evaluation of different variables between RA patients with and without FSD

\begin{tabular}{|c|c|c|c|c|c|c|c|c|c|c|c|c|}
\hline \multirow[b]{2}{*}{ Variables } & \multicolumn{5}{|c|}{ RA patients with FSD $(n=102)$} & \multicolumn{5}{|c|}{ RA patients without FSD $(n=49)$} & \multirow[b]{2}{*}{$t / Z / \chi^{2}$} & \multirow[b]{2}{*}{$p$} \\
\hline & $\mathrm{n}$ & $\%$ & Mean $\pm S D$ & Median & IQR & $\mathrm{n}$ & $\%$ & Mean \pm SD & Median & IQR & & \\
\hline Age (year) & & & $47.5 \pm 8.8$ & & & & & $43.8 \pm 7.8$ & & & 2.55 & $0.012^{*}$ \\
\hline BMI $\left(\mathrm{kg} / \mathrm{m}^{2}\right)$ & & & $23.5 \pm 3.9$ & & & & & $21.8 \pm 2.7$ & & & 2.66 & $0.010^{*}$ \\
\hline $\begin{array}{l}\text { Education level }(\%) \\
\leq 9 \text { years } \\
>9 \text { years }\end{array}$ & $\begin{array}{l}71 \\
31\end{array}$ & $\begin{array}{l}68.6 \\
31.4\end{array}$ & & & & $\begin{array}{l}28 \\
21\end{array}$ & $\begin{array}{l}57.1 \\
42.9\end{array}$ & & & & 2.28 & 0.131 \\
\hline $\begin{array}{l}\text { Occupational status (\%) } \\
\text { Employed } \\
\text { Unemployed }\end{array}$ & $\begin{array}{l}59 \\
43\end{array}$ & $\begin{array}{l}57.8 \\
42.2\end{array}$ & & & & $\begin{array}{l}35 \\
14\end{array}$ & $\begin{array}{l}71.4 \\
28.6\end{array}$ & & & & 2.60 & 0.107 \\
\hline $\begin{array}{l}\text { Average annual } \\
\text { income yuan (\%) } \\
\quad<15,000 \\
\quad \geq 15,000\end{array}$ & $\begin{array}{l}57 \\
45\end{array}$ & $\begin{array}{l}55.9 \\
44.1\end{array}$ & & & & $\begin{array}{l}17 \\
32\end{array}$ & $\begin{array}{l}34.7 \\
65.3\end{array}$ & & & & 5.95 & $0.015^{*}$ \\
\hline Religious beliefs (\%) & 9 & 8.8 & & & & 7 & 14.3 & & & & 1.04 & 0.307 \\
\hline Smoking use (yes) & 0 & 0 & & & & 1 & 2.0 & & & & 2.10 & 0.148 \\
\hline Menopausal status (yes) & 56 & 54.9 & & & & 13 & 26.5 & & & & 10.89 & $0.001^{*}$ \\
\hline Morning stiffness (min) & & & & 20 & 60 & & & & 5 & 30 & -1.85 & 0.064 \\
\hline Disease duration (year) & & & & 6.5 & 14.1 & & & & 3 & 11.3 & -2.64 & $0.008^{*}$ \\
\hline DMARDS use (\%) & 96 & 94.1 & & & & 44 & 89.8 & & & & 0.92 & 0.339 \\
\hline NSAIDS use (\%) & 40 & 39.2 & & & & 18 & 36.7 & & & & 0.09 & 0.769 \\
\hline Corticosteroids use (\%) & 48 & 47.1 & & & & 28 & 57.1 & & & & 1.35 & 0.246 \\
\hline HAQ-DI score & & & & 0.5 & 1.0 & & & & 0.1 & 0.3 & -3.77 & $0.000^{* * *}$ \\
\hline DAS28 & & & & 4.1 & 1.3 & & & & 3.6 & 1.2 & 2.42 & $0.017^{*}$ \\
\hline VAS pain (range 0-100) & & & & 6 & 4 & & & & 5 & 3.5 & -1.35 & 0.179 \\
\hline Confrontation & & & & 21 & 5 & & & & 22 & 5.5 & -0.33 & 0.744 \\
\hline Avoidance & & & & 17 & 4 & & & & 17 & 3.5 & -0.49 & 0.625 \\
\hline Resignation & & & & 10 & 5 & & & & 7 & 5 & -4.52 & $0.000^{* * *}$ \\
\hline HADS-Anxiety & & & & 49 & 48 & & & & 9 & 18.4 & 12.32 & $0.000^{* * *}$ \\
\hline HADS-Depression & & & & 33 & 32.4 & & & & 6 & 12.2 & 6.99 & $0.008^{*}$ \\
\hline Self-esteem score & & & & 30 & 5 & & & & 32 & 3 & -4.10 & $0.000^{* *}$ \\
\hline PCS & & & & 39 & 24 & & & & 52 & 34 & -3.70 & $0.000^{* * *}$ \\
\hline MCS & & & & 44 & 34 & & & & 63 & 28 & -2.89 & $0.004^{*}$ \\
\hline Marital dysfunction & 35 & 34.3 & & & & 1 & 2.0 & & & & 18.99 & $0.000^{* * *}$ \\
\hline
\end{tabular}

FSD: Female sexual dysfunction; SD: Standard deviation; IQR: Interquartile range; BMI: Body mass index; DMARDS: Disease modifying anti-rheumatic drugs; NSAIDS: Non-steroidal anti-inflammatory Drugs; HAQ-DI: Health Assessment Questionnaire-Disability Index; DAS28: Disease Activity Score in 28 joints; VAS: Visual Analog Scale; HADS: Hospital Anxiety and Depression Scale; PCS: Physical components summary; MCS: Mental components summary; Self-esteem: Rosenberg Self Esteem Scale; ${ }^{*} \mathrm{p}<0.001$. 


\begin{tabular}{|c|c|c|c|c|c|c|}
\hline & \multirow[b]{2}{*}{ B } & \multirow[b]{2}{*}{ SE } & \multirow[b]{2}{*}{$\mathrm{P}$} & \multirow[b]{2}{*}{$\operatorname{Exp}(B)$} & \multicolumn{2}{|c|}{$95 \% \mathrm{CI}$} \\
\hline & & & & & Lower & Higher \\
\hline Body mass index & -0.186 & 0.071 & $0.009^{*}$ & 0.831 & 0.722 & 0.955 \\
\hline Resignation & -0.320 & 0.089 & $0.000^{\text {*** }}$ & 0.726 & 0.610 & 0.865 \\
\hline Physical components summary & 0.034 & 0.017 & $0.042^{*}$ & 1.034 & 1.001 & 1.069 \\
\hline Mental components summary & -0.028 & 0.015 & 0.063 & 0.972 & 0.944 & 1.001 \\
\hline Marital dysfunction & -1.205 & 0.517 & $0.020^{*}$ & 0.300 & 0.109 & 0.825 \\
\hline Postmenopausal status & 1.515 & 0.498 & $0.002^{*}$ & 4.552 & 1.716 & 12.072 \\
\hline Constant & 5.845 & 2.394 & 0.015 & 345.389 & & \\
\hline $\mathrm{R}^{2}$ & 0.405 & & & & & \\
\hline
\end{tabular}

\section{Statistical analysis}

Statistical analysis was performed using the IBM SPSS version 20.0 software (IBM Corp., Armonk, NY, USA). For continuously and normally distributed variables, we used mean \pm standard deviation and independentsamples t-test group to recognize differences between groups. For non-normally distributed data, we used median and interquartile range while group differences were assessed by MannWhitney $\mathrm{U}$ test. For categorical variables, we used frequencies (\%) and the group differences were measured by Chi-square test. All the significant variables that were shown in the independent sample were included into the backward stepwise binary logistic regression model. Statistical significance was considered when $\mathrm{p}<0.05$ (two-sided).

\section{RESULTS}

Table 1 shows the socio-demographic, clinical and psychological data of patients and controls. The mean disease duration of RA patients was 5 years. There were no significant differences between the baselines in two groups such as age, BMI, educational level, occupational status, average annual income, menopausal status, religious beliefs and smoking use ( $p>0.05$ ). There were significant differences for other self-reported variables such as anxiety, depression, self-esteem and the number of subjects with marital dysfunction $(\mathrm{p}<0.05)$.
Table 2 shows the rate of FSD and the subscale and total scores of FSFI between RA and control groups. There were statistically significant differences between two groups including the total score, the subscale score of FSFI and the rate of FSD $(\mathrm{p}<0.05)$.

Table 3 represents the possible differences between RA patients with or without FSD. Obviously, patients with FSD had older age, higher BMI, lower annual income per year, longer disease duration, lower level of quality from both PCS and MCS in SF-36 questionnaire, with a trend toward higher rate of postmenopausal status, marital dysfunction, disease activity, physical dysfunction, resignation coping styles and other psychological problems such as anxiety, depression and low self-esteem $(p<0.05)$.

To identify the risk factors of FSD in patients, we used the backward stepwise binary logistic regression model in Table 4 . We found that BMI, resignation coping style, PCS, marital dysfunction and postmenopausal status were the predictors of FSD.

\section{DISCUSSION}

To our knowledge, this is the first study investigating the prevalence and potential risk factors (e.g. coping style, marital quality, disease activity levels) of FSD in RA patients from mainland China. As described previously, RA patients in the current study had poorer sexual function than the norm, ${ }^{34-36}$ including higher 
level of sexual dysfunction in all domains of FSFI scale and higher rate of FSD. Despite all of these findings highlighting the high prevalence of FSD in Chinese mainland patients with RA, FSD has still not been included as part of the routine care for detection and management. ${ }^{37}$ Hence, healthcare professionals should not only focus on the physical limitations of RA patients, but also investigate FSD in their regular outpatient examination.

There are many reasons that may lead to FSD such as demographic characteristics, physical function, psychological problems, disease activity and drug usage etc. ${ }^{14-17}$ Our univariate analysis of demographic factors was consistent with previous studies showing that patients with FSD had older age and lower education and income levels. ${ }^{13,14}$ For other physical, psychological and life quality variables, we found that patients with FSD had higher levels of anxiety, depression and lower levels of PCS and MCS from SF-36. It may be concluded that patients with poor physical and psychological functions may have difficulty engaging in daily life, including sex life. It is not surprising to find that lower physical function and higher disease duration and disease activity were closely related to FSD. A possible explanation for such correlation is that when RA progresses, the joints will be more and more affected, which may indirectly cause FSD.

In our study, except demographic, physical, psychological and clinical factors that may lead to FSD, we also included marital quality and coping style which were rarely reported. Marital quality is important because of the potential negative effect on patients. ${ }^{38,39}$ Researchers to date have tended to focus on marital quality in RA couples rather than the impact of marital quality on FSD in RA patients. ${ }^{20,40}$ Therefore, it would be interesting to assess the effects of marital quality on FSD. Our backward stepwise binary logistic regression indicated that marital quality correlated positively with FSD, which was in accordance with the study by Dombek et al., ${ }^{41}$ stating that marital quality had a significant effect on FSD. And, considering that marital quality was poorly understood, ${ }^{42}$ health professionals should pay more attention to patients with poor marital quality.

As part of their study limitations, Lin et al. ${ }^{23}$ argued that future studies should include coping effectiveness, which represents participants' willingness to choose the specific coping style for a particular medical event. ${ }^{43}$ This was rarely studied in terms of FSD. Similar to the findings of the few studies on this topic, ${ }^{21}$ we found that resignation coping style positively affected FSD in RA patients. Therefore, this offers important insight into the significance of resignation coping style on healthcare professionals.

Other risk factors in our study such as postmenopausal status also had a positive effect on FSD, which was shown in a previous study due to neurogenic, psychological, metabolic, vasomotor and psychosomatic disorders. ${ }^{41}$ This finding suggested that healthcare professionals should attach great importance to such patients, particularly to those with older age. Consistent with a previous study, ${ }^{16}$ there was a negative connection between BMI and FSD, the reason for which was because a heavier person might have difficulty when changing postures during sexual intercourse. This indicates that healthcare professionals should carefully screen out patients with higher BMI and apply early interventions to reduce $\mathrm{BMI}$.

This study has some limitations. Firstly, functional disability and psychological factors were measured by self-reported questionnaires. Secondly, study samples were from a single hospital in Southeast mainland China. In addition, the majority of patients were inpatients, and some patients with a milder disease may have been overlooked (less likely to be attending outpatient reviews very often, less likely to be an inpatient; therefore, possibly less likely to be invited to participate in this study). Findings of this study cannot be generalized to all RA patients in our society. Thirdly, the cross-sectional design does not allow examining causal relationships between variables. Further prospective studies with expanded sample sizes and objective sexual measures should be conducted to support the development of effective interventions to improve sexual function of RA patients.

In conclusion, RA negatively affected sexual function of patients who had considerably impaired sexual function compared to controls in our study. Measuring sexual function should be considered a vital part of the comprehensive evaluation of the health status of RA patients, which may contribute 
some valuable clues to improved management of the disease and treatment decisions.

\section{Acknowledgements}

We would like to thank all participants included in our study.

\section{Declaration of conflicting interests}

The authors declared no conflicts of interest with respect to the authorship and/or publication of this article.

\section{Funding}

The authors received no financial support for the research and/or authorship of this article.

\section{REFERENCES}

1. Araki Y, Mimura T. The Mechanisms Underlying Chronic Inflammation in Rheumatoid Arthritis from the Perspective of the Epigenetic Landscape. J Immunol Res 2016;2016:6290682.

2. Alpízar-Rodríguez D, Pluchino N, Canny G, Gabay C, Finckh A. The role of female hormonal factors in the development of rheumatoid arthritis. Rheumatology (Oxford) 2017;56:1254-63.

3. Hill J, Bird H, Thorpe R. Effects of rheumatoid arthritis on sexual activity and relationships. Rheumatology (Oxford) 2003;42:280-6.

4. Gong G, Mao J. Health-related quality of life among chinese patients with rheumatoid arthritis: the predictive roles of fatigue, functional disability, selfefficacy, and social support. Nurs Res 2016;65:55-67.

5. Östlund G, Björk M, Valtersson E, Sverker A. Lived experiences of sex life difficulties in men and women with early RA - The Swedish TIRA project. Musculoskeletal Care 2015;13:248-57.

6. Tristano AG. The impact of rheumatic diseases on sexual function. Rheumatol Int 2009;29:853-60.

7. Can AG, Günendi Z. Prognostic factors in rheumatoid arthritis. Rheumatology 2008;23:60-2.

8. El Miedany Y, El Gaafary M, El Aroussy N, Youssef S, Ahmed I. Sexual dysfunction in rheumatoid arthritis patients: arthritis and beyond. Clin Rheumatol 2012;31:601-6.

9. Tristano AG. Impact of rheumatoid arthritis on sexual function. World J Orthop 2014;5:107-11.

10. Ryan S, Wylie E. An exploratory survey of the practice of rheumatology nurses addressing the sexuality of patients with rheumatoid arthritis. Musculoskeletal Care 2005;3:44-53.

11. Ferreira Cde C, da Mota LM, Oliveira AC, de Carvalho JF, Lima RA, Simaan CK, et al. Frequency of sexual dysfunction in women with rheumatic diseases. Rev Bras Reumatol 2013;53:35-46.
12. Aras $\mathrm{H}$, Aras B, Icagasioglu A, Yumusakhuylu Y, Kemahli E, Haliloglu S, et al. Sexual dysfunction in women with rheumatoid arthritis. Med Glas (Zenica) 2013;10:327-31.

13. Hari A, Rostom S, Lahlou R, Bahiri R, HajjajHassouni N. Sexual function in Moroccan women with rheumatoid arthritis and its relationship with disease activity. Clin Rheumatol 2015;34:1047-51.

14. Shahar MA, Hussein H, Sidi H, Shah SA, Mohamed Said MS. Sexual dysfunction and its determinants in Malaysian women with rheumatoid arthritis. Int $\mathrm{J}$ Rheum Dis 2012;15:468-77.

15. Coskun B, Coskun BN, Atis G, Ergenekon E, Dilek $\mathrm{K}$. Evaluation of sexual function in women with rheumatoid arthritis. Urol J 2014;10:1081-7.

16. Yilmaz H, Polat HA, Yilmaz SD, Erkin G, Kucuksen $\mathrm{S}$, Salli $\mathrm{A}$, et al. Evaluation of sexual dysfunction in women with rheumatoid arthritis: a controlled study. J Sex Med 2012;9:2664-70.

17. Josefsson KA, Gard G. Sexual health in patients with rheumatoid arthritis: experiences, needs and communication with health care professionals. Musculoskeletal Care 2012;10:76-89.

18. Kobelt G, Texier-Richard B, Mimoun S, Woronoff AS, Bertholon DR, Perdriger A, et al. Rheumatoid arthritis and sexuality: a patient survey in France. BMC Musculoskelet Disord 2012;13:170.

19. Tasiemski T, Angiaszwili-Biedna N, Wilski M. Assessment of objective and subjective quality of life in people with rheumatoid arthritis - preliminary study. Ortop Traumatol Rehabil 2009;11:346-59.

20. van Lankveld W, Ruiterkamp G, Näring G, de Rooij DJ. Marital and sexual satisfaction in patients with RA and their spouses. Scand J Rheumatol 2004;33:405-8.

21. Wiltink J, Subic-Wrana C, Tuin I, Weidner W, Beutel ME. Repressive coping style and its relation to psychosocial distress in males with erectile dysfunction. J Sex Med 2010;7:2120-9.

22. Fahami F, Mohamadirizi S, Savabi M. The relationship between sexual dysfunction and quality of marital relationship in genital and breast cancers women. $\mathrm{J}$ Educ Health Promot 2017;6:56.

23. Lin MC, Lu MC, Livneh H, Lai NS, Guo HR, Tsai TY. Factors associated with sexual dysfunction in Taiwanese females with rheumatoid arthritis. BMC Womens Health 2017;17:12.

24. Prevoo ML, van 't Hof MA, Kuper HH, van Leeuwen MA, van de Putte LB, van Riel PL. Modified disease activity scores that include twenty-eight-joint counts. Development and validation in a prospective longitudinal study of patients with rheumatoid arthritis. Arthritis Rheum 1995;38:44-8.

25. Koh ET, Seow A, Pong LY, Koh WH, Chan L, Howe HS, et al. Cross cultural adaptation and validation of the Chinese Health Assessment Questionnaire for use in rheumatoid arthritis. J Rheumatol 1998;25:1705-8.

26. Rosen R, Brown C, Heiman J, Leiblum S, Meston C, Shabsigh $\mathrm{R}$, et al. The Female Sexual Function Index 
(FSFI): a multidimensional self-report instrument for the assessment of female sexual function. J Sex Marital Ther 2000;26:191-208.

27. Lau Y, Wang Y, Yin L, Chan KS, Guo X. Validation of the Mainland Chinese version of the Edinburgh Postnatal Depression Scale in Chengdu mothers. Int $\mathrm{J}$ Nurs Stud 2010;47:1139-51.

28. Lau Y, Yin L, Wang Y. Severe antenatal depressive symptoms before and after the 2008 Wenchuan earthquake in Chengdu, China. J Obstet Gynecol Neonatal Nurs 2011;40:62-74.

29. Zhang SJ, Huang LH, Wen YL, Hu ZH, Jin J, Shen LH, et al. Impact of personality and coping mechanisms on health related quality of life in liver transplantation recipients. Hepatobiliary Pancreat Dis Int 2005;4:356-9.

30. Watson R. A psychometric evaluation of the Chinese version of the Hospital Anxiety and Depression Scale in patients with coronary heart disease. J Clin Nurs 2009;18:3068.

31. Bjelland I, Dahl AA, Haug TT, Neckelmann D. The validity of the Hospital Anxiety and Depression Scale. An updated literature review. J Psychosom Res 2002;52:69-77.

32. Li L, Wang HM, Shen Y. Chinese SF-36 Health Survey: translation, cultural adaptation, validation, and normalisation. J Epidemiol Community Health 2003;57:259-63.

33. Piyavhatkul N, Aroonpongpaisal S, Patjanasoontorn N, Rongbutsri S, Maneeganondh S, Pimpanit W. Validity and reliability of the Rosenberg SelfEsteem Scale-Thai version as compared to the Self-Esteem Visual Analog Scale. J Med Assoc Thai 2011;94:857-62.

34. Bartellas E, Crane JM, Daley M, Bennett KA, Hutchens D. Sexuality and sexual activity in pregnancy. BJOG 2000;107:964-8.
35. Areskoug-Josefsson K, Oberg U. A literature review of the sexual health of women with rheumatoid arthritis. Musculoskeletal Care 2009;7:219-26.

36. Zhang Q, Zhou C, Chen H, Zhao Q, Li L, Cui Y, et al. Rheumatoid arthritis is associated with negatively variable impacts on domains of female sexual function: evidence from a systematic review and meta-analysis. Psychol Health Med 2018;23:114-25.

37. Britto MT, Rosenthal SL, Taylor J, Passo MH. Improving rheumatologists' screening for alcohol use and sexual activity. Arch Pediatr Adolesc Med 2000;154:478-83.

38. Zautra AJ, Hoffman JM, Matt KS, Yocum D, Potter PT, Castro WL, et al. An examination of individual differences in the relationship between interpersonal stress and disease activity among women with rheumatoid arthritis. Arthritis Care Res 1998;11:271-9.

39. Waltz M, Kriegel W, van't Pad Bosch P. The social environment and health in rheumatoid arthritis: marital quality predicts individual variability in pain severity. Arthritis Care Res 1998;11:356-74.

40. Tewary S, Farber N. Marital quality and self-efficacy: influence on disease management among individuals with rheumatoid arthritis. J Evid Based Soc Work 2014;11:237-47.

41. Dombek K, Capistrano EJ, Costa AC, Marinheiro LP. Risk factors associated with sexual dysfunction in Brazilian postmenopausal women. Int J Impot Res 2016;28:62-7.

42. Bermas BL, Tucker JS, Winkelman DK, Katz JN. Marital satisfaction in couples with rheumatoid arthritis. Arthritis Care Res 2000;13:149-55.

43. Wu Z, Liu Y, Li X, Li X. Resilience and Associated Factors among Mainland Chinese Women Newly Diagnosed with Breast Cancer. PLoS One 2016;11:e0167976. 